Revista do SELL

v. $4, n^{\circ} .1$

ISSN: $1983-3873$

\title{
POSICIONANDO-SE FRENTE À DIVERSIDADE LINGUÍSTICA: O CASO DO ESPANHOL COMO LÍNGUA ESTRANGEIRA
}

\author{
PLACING TO THE LINGUISTIC DIVERSITY: THE CASE OF SPANISH AS A FOREIGN \\ LANGUAGE
}

\author{
Leandro Silveira de Araujo \\ UFU \\ Rafaela Giacomin Bueno \\ UNESP - Araraquara
}

RESUMO: O trabalho visa empreender uma reflexão acerca de fatores que contribuem para constituição da identidade (e subjetividade) na aprendizagem de espanhol como língua estrangeira. Assim, suscitamos algumas questões linguísticas e extralinguísticas que estejam atreladas ao ensino do espanhol no Brasil, a fim de compreender as razões que motivam o aluno a se identificar com uma variedade do espanhol em detrimento de outra.

PALAVRAS-CHAVE: Variação Linguística; Identidade; Ensino de Língua Espanhola.

ABSTRACT: This article aims at providing a reflection about the factors that contribute to the identity and subjectivity constitution in the learning of Spanish as a foreign language. Then, we evoke some linguistic and extralinguistic questions that are linked to the teaching of Spanish in Brazil to understand the reasons that foster the student to identify himself or herself with one variety of Spanish instead of another one.

KEYWORDS: Linguistic Variation, Identity, Teaching of Spanish.

\section{A língua e o homem: uma existência em eterna construção}

O desenvolvimento da linguagem está tão inextricavelmente ligado ao da personalidade de cada indivíduo, da terra natal, da nação, da humanidade, da própria vida, que é possível indagar-se se ela não passa de um simples reflexo ou se ela não é tudo isso: a própria fonte do desenvolvimento dessas coisas (HJELMSLEV, 1975, p. 1).

A descrição do linguista dinamarquês mostra-nos como o homem e a linguagem traçam uma relação simbiótica, na qual a linguagem não é uma ferramenta criada simplesmente para suprir a necessidade humana de dar forma a seus pensamentos e de se comunicar com o outro. Indo muito além disso, a linguagem se instauraria de forma ativa em toda experiência vivenciada pelo sujeito, refletindo traços que compõem as características de cada um de seus falantes. É nessa interação vívida existente entre 


\section{Revista do SELL}

v. $4, n^{\circ} .1$

ISSN: $1983-3873$

homem e linguagem que devemos compreender o comportamento desse complexo organismo que é a língua. Isso porque, uma vez inseparáveis, homem e língua passam a percorrer o mesmo trajeto de vida, apresentando reações e comportamentos que seguem em uma mesma direção.

Devido a essa relação simbiótica, podemos contemplar, na língua, a impressão de marcas provenientes de características próprias de um indivíduo e das comunidades nas quais se insere. Assim, é natural que a dinamicidade e a complexidade da sociedade à qual pertence $o$ falante interfiram na língua, transformando-a em um ser profundamente heterogêneo. Observemos como as palavras da música "Todo cambia" ilustram essa relação de mutabilidade espelhada:

Cambia lo superficial/Cambia también lo profundo/Cambia el modo de pensar/Cambia todo en este mundo/[...].

Cambia el rumbo el caminante/Aunque esto le cause daño/Y así como todo cambia/Que yo cambie no es extraño/ [...].

Lo que cambió ayer/Tendrá que cambiar mañana/Así como cambio yo En esta tierra lejana [...].

Cambia todo cambia (NUMHAUSER, 1995).

É muito provável que ao compô-la, Julio Numhauser não visualizava na língua a figura do eu-lírico. No entanto, se damos voz à língua, atribuindo-lhe supostamente as palavras de "todo cambia", vislumbraremos a defesa de um organismo vivo que, contra qualquer tentativa de inibição de sua sobrevivência, grita justificando seu comportamento. Dessa maneira, do mesmo modo que continuamente muda o individuo ("caminante") e seu entorno social ("todo en ese mundo") não é estranho que também mude quem o acompanha: a língua. Em síntese, tal como o homem em convívio social, a língua mostrase também em um fazer permanente que é regido pelas necessidades linguísticas da comunidade da qual é mãe.

A Sociolinguística e a Geolinguística mostram-nos que a origem geográfica, o status socioeconômico, o grau de escolarização, a idade, o sexo, o mercado de trabalho, o monitoramento estilístico e as redes sociais do falante são alguns dos principais fatores extralinguísticos que favorecem a variação no uso da língua. Nosso propósito nesse trabalho é o de refletir sobre as variedades da língua espanhola e o seu ensino no Brasil, para tanto, escolhemos nos atentar à variação linguística horizontal, isto é, ao uso verificável nas diferentes regiões diatópicas onde a língua espanhola é falada. 


\section{Revista do SELL}

v. $4, n^{\circ} .1$

ISSN: $1983-3873$

\section{A relevância do espaço na abordagem social da linguagem}

Caravedo (2004) nos mostra que costumeiramente se deixou de lado a observação do aspecto geográfico da variação linguística. Para o autor, a atitude de desprezo deve ser reavaliada porque a variação espacial é tida como um dos aspectos mais evidentes da heterogeneidade na língua. Nem mesmo dentro dos procedimentos da Sociolinguística o espaço é tomado como um fator condicionante da variação, mas somente como um localizador dos fenômenos analisados.

A evidência com que se dá a variação no âmbito geográfico pode ser alcançada grosso modo pela maneira como os próprios falantes da língua a percebem. Nesse sentido, Caravedo (2004) explica-nos que

[...] los hablantes de una lengua tienen una percepción más amplia del espacio (sea de tipo suprarregional, nacional o incluso transnacional), y que la variación diatópica aparece como inmediatamente reconocible por todos. Los individuos desarrollan en general una percepción muy refinada de lo propio y de lo ajeno [..] (CARAVEDO, 2004, p.1122) ${ }^{1}$.

É por isso que, mesmo dentro de um território nacional, as regiões geográficas adquirem um valor simbólico, que não é determinado somente pelas características geográficas, climáticas, vegetais, entre outras, que possui o espaço, mas também por uma conceitualização estereotipada dos habitantes locais.

Para o autor, o espaço pode ser visto também a partir da perspectiva social, uma vez que "remite principalmente a una sociedad (o a varias) que habitan dentro de determinados límites geográficos". Desse modo, ele não será somente um mero instrumento de localização de fenômenos, mas "se entenderá como una variable dependiente de lo social" (CARAVEDO, 2004, p.1123).

Nesse sentido, na observação da variação diatópica, a mobilidade dos habitantes e a capacidade de se relacionar com membros de outros espaços são comportamentos que devem ser considerados atentamente, pois viabilizarão a transformação interna dos espaços. Sobre as consequências advindas desse contato inter-regional, Camacho (2001) afirma:

\footnotetext{
${ }^{1}<$ Tradução nossa>"[...] os falantes de uma língua têm uma percepção mais ampla do espaço (seja do tipo suprarregional, nacional ou até mesmo transnacional), e que a variação diatópica aparece como imediatamente reconhecível por todos. Os indivíduos desenvolvem, em geral, uma percepção muito refinada do próprio e do distante [...]" (CARAVEDO, 2004, p.1122).
} 


\section{Revista do SELL \\ v. $4, n^{\circ} .1$ \\ ISSN: $1983-3873$}

Como é verdadeiro que o domínio de uma língua deriva do grau de contato do falante com outros membros da comunidade, também é verdadeiro que quanto maior o intercâmbio entre os falantes de uma língua, tanto maior a semelhança entre seus atos verbais. Dessa tendência para a maior semelhança entre os atos verbais dos membros de uma mesma comunidade resulta a variação geográfica (CAMACHO, 2001, p.58).

A fim de ilustrarmos sinteticamente a complexidade que envolve o estudo das variedades dialetais da língua espanhola, esboçamos, a seguir, as principais propostas de divisão dialetal do idioma. Esperamos, assim, conseguir estabelecer um quadro que nos conduza a uma visão introdutória da heterogeneidade da língua nessa multicultural sociedade. Em seguida, procederemos a uma breve discussão sobre Identidade e Preconceito Linguísticos, culminando numa reflexão sobre as relações de identidade dos estudantes com as variedades dialetais apresentadas.

\section{A dialetologia hispânica}

\subsection{Henríquez Ureña (1976): um estudo inaugurador e provisório}

O provisório trabalho de Henríquez Ureña (1976) visava impulsionar o desenvolvimento da dialetologia hispano-americana, dando-lhe, posteriormente, um caráter mais empírico à medida que se somassem a ele novos estudos. Observando efetivamente a proposta, vejamos como se dividiria dialetalmente a América hispânica:

Provisionalmente me arriesgo a distinguir en la América española cinco zonas principales: primera, la que comprende las regiones bilingües del Sur y Sudoeste de los Estados Unidos, México y las Repúblicas de la América Central; segunda, las tres Antillas españolas (Cuba, Puerto Rico y la República Dominicana, la antigua parte española de Santo Domingo), la costa y los llanos de Venezuela y probablemente la porción septentrional de Colombia; tercera, la región andina de Venezuela, el interior y la costa occidental de Colombia, el Ecuador, el Perú, la mayor parte de Bolivia y tal vez el Norte de Chile; cuarta, la mayor parte de Chile; quinta, la Argentina, el Uruguay, el Paraguay y tal vez parte del Sudeste de Bolivia. (HENRIQUEZ UREÑA, 1976, p.5)².

\footnotetext{
${ }^{2}<$ Tradução nossa> "Provisionalmente, arrisco-me a distinguir na América espanhola cinco zonas principais: primeira, a que compreende as regiões bilíngues do sul e sudoeste dos Estados Unidos, México e as Repúblicas da AméricaCentral; segunda, as três Antilhas espanholas (Cuba, Porto Rico e a República Dominicana, a antiga parte espanhola de Santo Domingo), a costa e as planícies da Venezuela e provavelmente a porção setentrional da Colômbia; terceira, a região andina da Venezuela, o interior e a costa ocidental da Colômbia, o Equador, o Peru, a maior parte da Bolívia e talvez o norte do Chile; quarta, a maior parte do Chile; quinta, a Argentina, o Uruguai, o Paraguai e talvez parte do Sudeste da Bolívia” (HENRÍQUEZ UREÑA, 1976, p.5).
} 


\section{Revista do SELL}

v. $4, n^{\circ} .1$

ISSN: $1983-3873$

\subsection{MONTES GIRALDO (1987): a bipartição dialetal do espanhol}

Considerando não só fenômenos linguísticos, mas também fatores sócio-históricos, Montes Giraldo (1987) verifica que, tanto na América como na Península, a língua espanhola pode ser agrupada em duas macrorregiões dialetais - os chamados superdialetos. Além disso, o autor mostra-nos em sua proposta de bipartição dialetal a existência de uma relação direta entre o novo e o antigo mundo.

Deste modo, o superdialeto $A$ recebe o nome de espanhol serrano, central, ou ainda interiorano, já que se localiza no centro-norte da Espanha e nas terras altas e interiores da América. Segundo o autor, essa região dialetal caracteriza-se, entre outros, pela conservação da $-s$ (sibilante) como implosiva e da identidade fonológica de $[r]$ e [l]. Por outro lado, o superdialeto $B$, conhecido como espanhol meridional, atlântico, costeiro ou ainda como o das terras baixas, predomina na parte meridional da Espanha e nas llhas Canárias. Na América, por sua vez, é a variedade observada no Caribe, no litoral e, eventualmente, em comunidades ribeirinhas. Fundamentalmente, esse superdialeto se caracteriza pela aspiração ou apagamento do fonema /s/ no contexto pós-silábico e neutralização parcial de [r] e [I] (MONTES GIRALDO, 1987, p.214 e 215).

A síntese do postulado do autor mostra-nos que tanto na América como na Península, é possível observar uma variedade com características mais conservadoras (superdialeto $A$ ) e uma variedade mais inovadora (superdialeto $B$ ).

\subsection{MORENO FERNÁNDEZ (2000): uma proposta pan-hispânica}

A última proposta do presente esboço também propõe dividir a língua espanhola usada tanto na América como na Península. Com este fim, a partir da análise de fenômenos fonéticos, fonológicos, gramaticais e lexicais, Moreno Fernández (2000) sugere a divisão do espanhol em oito zonas, sendo três delas localizadas na Europa (E.1. Español Castellano; E.2. Español de Andalucía; E.3. Español de Canarias) e cinco na América (A.1. Español de Caribe; A.2. Español de México y Centroamérica; A.3. Español de los Andes; A.4. Español de la Plata y del Chaco; A.5. Español de Chile.

A síntese da análise das principais propostas de divisão dialetal do espanhol mostra-nos que a dialetologia hispano-americana sempre esteve na contramão de uma proposta homogeneizadora da língua. Atentando-nos ao valor desse tipo de estudo para o processo de ensino de espanhol para estrangeiros (E/LE), acreditamos que uma abordagem dialetológica no ensino de E/LE evitaria, pelo menos, afirmações errôneas de 


\section{Revista do SELL}

v. $4, n^{\circ} .1$

ISSN: $1983-3873$

que a língua espanhola tem um uso homogêneo ou, quando mais atentas, de que as variedades da língua espanhola estruturam-se sobre dois polos opositivos: o "espanhol na América" versus o "espanhol na Espanha". Conforme observamos desde Henríquez Ureña (1976), a diversidade cultural dos povos americanos implicou a formulação de diferentes padrões linguísticos na vastidão do continente. Da mesma maneira, Moreno Fernández (2000) indica-nos que na Espanha há normas linguísticas que se diferenciam de um lugar para outro, sem, por isso, impossibilitar uma relação com as variedades americanas - como muito bem nos mostra Montes Giraldo (1987).

Por fim, diante das propostas de divisão dialetal apresentadas nessa seção, observamos que a compreensão da diversidade linguística perpassa o conhecimento do uso efetivo da língua e sua relação com aspectos extralinguísticos. Assim sendo, como professores, faz-se imprescindível considerarmos essa heterogeneidade hispânica e suas implicações no ensino-aprendizagem da língua espanhola, isso porque cremos que, uma vez identificada essa pluralidade, bem como sua origem, conduzimos nossos alunos por um caminho livre de atitudes preconceituosas ou de generalizações que corram o risco de serem falsas.

\section{Identidade, Subjetividade e Aprendizagem de espanhol}

Há nos estudos de lingua(gem), bem como em outras áreas como Psicologia, Educação, Antropologia, Estudos Culturais, uma série de teorias que se propõem a discutir o termo identidade. Nesta seção, propomos pensar brevemente sobre identidade e subjetividade para o processo de ensino-aprendizagem de espanhol. Consideraremos os conceitos de identidade e subjetividade a partir do que nos apresenta GERALDI (2010) e a escritura bakhtiniana (BAKHTIN, 1926; 2006).

É relevante mencionarmos que o termo identidade não pode ser dissociado de questões que envolvam o sujeito e a linguagem. Partimos, pois, de uma concepção de linguagem como "processo de constituição da subjetividade", que "marca trajetórias individuais de sujeitos que se fazem sociais também pela língua que compartilham". (GERALDI, 2010). Neste sentido, procuraremos considerar a subjetividade, a partir das reflexões de BAKHTIN (2006), como uma base resultante de aspectos culturais e sociais experimentados pelo sujeito ao longo de sua história.

Considerando o vínculo indissociável que se estabelece entre sujeito, subjetividade e linguagem, tem-se, ainda, que a subjetividade não é acessível senão pela materialidade 


\section{Revista do SELL}

v. $4, n^{\circ} .1$

ISSN: $1983-3873$

que comporta a linguagem. Essa materialização, no entanto, não permite a compreensão do sujeito em sua totalidade, como algo acabado, visto que tanto a linguagem como o sujeito estão, através de constantes modificações, construindo-se no movimento que abarca o eu e o outro (GERALDI, 2010). É neste movimento de constituição mútua que a subjetividade se revela; sendo a identidade uma possível forma de sua manifestação, tal como destacamos neste trabalho.

A identidade pode se revelar, pois, por meio de relações dialógicas que, por sua vez, segundo BAKHTIN (1926), constroem relações de sentido que se realizam a partir de marcas verbais e não-verbais (marcas que contemplam o horizonte espacial comum dos interlocutores e que podem incluir, por exemplo, a linguagem gestual do sujeito).

Pensar, então, na constituição da identidade em aprendizes brasileiros adultos de E/LE implica, a nosso ver, levantar a hipótese de que, os sujeitos-aprendizes, através da língua(gem), poderão realizar escolhas de elementos (estruturas verbais e não-verbais) vinculados à língua e à cultura hispânica a que estão expostos. Deste modo, a expressão linguística e/ou não-linguística estará mediada por processos de identificação.

\section{Sobre políticas linguísticas: o caso da língua espanhola}

Com o propósito de refletir acerca de alguns fatores que contribuem para a constituição da identidade e subjetividade na aprendizagem de E/LE, faremos um breve exame sobre as políticas linguísticas na Espanha e suas repercussões no Brasil. Para tanto, é necessário considerar primeiramente que há, no Brasil, uma forte imagem de monolinguismo, contaminada por "jogos de poder", que cercam os discursos de falantes nativos de língua portuguesa (BAGNO, 2002).

Ao encontro dessa postura, acreditamos que a hegemonia que caracteriza a visão da língua portuguesa no Brasil se estende à visão que o aprendiz brasileiro tem da língua espanhola. Como explica GODOI (2010), esse discurso pode ser decorrente da prática de uma política linguística desenvolvida pela Espanha no Brasil. Observa-se nessa ação política a promulgação de um "paraíso comunicativo" que destaca, a partir de iniciativas de controle, a hegemonia do espanhol peninsular no mundo.

Quando o assunto é a promoção da língua, ainda hoje, a perspectiva econômica tem sido o foco de atenção de muitos organismos, agências e iniciativas espanholas. Há, portanto, uma política linguística voltada exclusivamente à expansão do poderio econômico do país. GODOI (2010) destaca algumas asseverações que, movidas por uma 


\section{Revista do SELL \\ v. $4, n^{\circ} .1$ \\ ISSN: $1983-3873$}

ganância econômica, refletem atitudes políticas que proporcionaram o abandono e o esquecimento das variedades não peninsulares do espanhol. Dentre elas, retoma a afirmação de José Rolando Alvarez (presidente da Fundação da Língua Espanhola), quem disse: Temos a oportunidade de que o espanhol seja o petróleo de Castela e Leão e, ainda, estudantes do mundo todo são precisamente os potenciais clientes desse negócio.

Engajadas nas vantagens econômicas que a língua pode oferecer, as políticas da Espanha incentivam o domínio do mercado editorial espanhol, produzindo cada vez mais livros didáticos e outros materiais com traços linguísticos exclusivamente da variedade castelhana. Ao difundirem apenas valores atrelados à cultura espanhola, esses materiais, na relação de aprendizagem que o sujeito estabelece com a língua, podem resultar em posturas estigmatizadas quanto aos outros povos hispano-falantes.

No Brasil, a Espanha se afirma no ensino de língua E/LE por meio de vantagens econômicas tentadoras, ofertas que os países hispano-americanos raramente proporcionam. Como resultado, observa-se, no Brasil, um crescente distanciamento dos países que o cerca, já que se evita a prática de ensino e aprendizagem do espanhol nãopeninsular bem como das práticas discursivas desses povos. Em última análise, a hegemonia do espanhol peninsular (de Castela e Leão) no ensino da língua no Brasil causa um apagamento da riqueza linguística e cultural que constitui a nossa diversidade identitária latino-americana (GODOI, 2010) e, também, a diversidade do próprio espanhol peninsular.

\section{Diversidade e preconceito linguísticos: temas para o ensino de E/LE}

Conceber uma única variedade da língua como um parâmetro de normalidade e excelência consiste em desautorizar e mascarar a heterogeneidade que a constitui e que a caracteriza no movimento entre indivíduos de distintas faixas etárias, classes sociais, espaços, tempos, entre outros. Como afirma FIORIN (2002, p.114), acreditamos que "as variedades não são feias ou bonitas, certas ou erradas, boas ou ruins, elegantes ou deselegantes; elas são simplesmente diferentes".

Observando o estigma que alunos adultos de E/LE atribuem a variedades não prestigiadas da língua, encontramos um comportamento semelhante à avaliação que muitos fazem da sua própria língua materna, o português brasileiro (PB). Isso porque, conforme aponta BAGNO (2002, p. 15), o PB é pensado majoritariamente pelos seus 


\section{Revista do SELL}

v. $4, n^{\circ} .1$

ISSN: $1983-3873$

falantes como uma língua homogênea a todo o país. Assim, a imagem do "Brasil monolíngue", principalmente sustentada pelos veículos de comunicação, estimula que muitos de seus falantes considerem sua língua como detentora de uma unidade surpreendente (MASSINI-CAGLIARI, 2004). Mito que, por um lado, dissimula, entre outros, a emergência de problemas sociais, culturais, históricos e, por outro lado, ameaça a educação brasileira em sua tarefa de promulgar e reconhecer a diversidade da língua portuguesa falada no Brasil.

No mesmo sentido, o ensino de línguas estrangeiras no Brasil - mais atentamente, o espanhol - também parece ignorar a heterogeneidade da língua estudada. Tanto é assim que poucos são os momentos em que se abre espaço para a reflexão sobre as variedades linguísticas. Tal omissão resulta muitas vezes na manutenção de posturas de depreciação das variedades não consideradas padrão.

Segundo nos explica MASSINI-CAGLIARI (2004), cabe também à escola romper com os estigmas sobre as variedades menos prestigiadas. Para a autora, o cumprimento dessa missão seria possível a partir do desenvolvimento de reflexões consistentes sobre a natureza da linguagem. Tanto é assim que afirma que "social and linguistic prejudices generated by prescriptivism could naturally disappear and be beaten by the development of linguistic research and more scientifically based educational system" (MASSINICAGLIARI, 2004, p. 16).

A tentativa dos docentes de suscitar no ensino de E/LE uma consciência sobre a diversidade da língua não se restringe apenas em por à vista de seus alunos que o espanhol, por ser uma língua falada em mais de vinte países, apresenta variações em diferentes níveis de análise linguística (fonético, fonológico, morfológico, sintático, entre outros). Mas, consiste, também, em alertá-los sobre a relevância social e pragmática que o conhecimento da heterogeneidade linguística implica, haja vista que é pela e na complexidade da língua que podemos refletir acerca de como se configuram outras visões de mundo e como elas se organizam no sistema linguístico.

Assim, o ensino de espanhol no Brasil não se justificaria exclusivamente pelas fortes relações econômicas que o Brasil estabelece com os países hispânicos com que faz fronteira (lembremo-nos especialmente do Mercosul), mas também pela-contribuição social que o estudo da língua espanhola pode aportar à formação dos brasileiros. Isso porque se faz necessário que o brasileiro conheça a língua de seus vizinhos, uma vez que há uma proximidade entre nossas culturas. Desse modo, entenderíamos melhor aquilo que nos é comum e aquilo que nos difere. 


\section{0 estudo dos posicionamentos de aprendizes de E/LE frente às variedades da língua}

\subsection{Situando o estudo}

Para levar a cabo as discussões que promovemos ao longo do texto, analisaremos um questionário aplicado aos alunos de língua espanhola do Laboratório de Línguas (LABLIN) da Faculdade de Ciências Agronômicas (FCA - Botucatu), em colaboração com a Faculdade de Ciências e Letras (FCL- Araraquara) - instituições pertencentes à Universidade Estadual Paulista "Júlio de Mesquita Filho" (UNESP).

O quadro de alunos que compõem os cursos de língua do LABLIN é constituído preponderantemente por graduandos dos cursos de agronomia e engenharia florestal. Segue a esse grupo, os pós-graduandos da área de ciências agrárias e os funcionários da instituição. Juntos, os três perfis constituem um grupo de faixa etária entre 17 e 50 anos. Acrescentamos ainda que, com exceção dos alunos em formação, todos os demais participantes do projeto apresentam nível superior completo e totalizam um número de 68 alunos na área de espanhol ${ }^{3}$.

Tendo em vista a relevância do estudo da heterogeneidade linguística e as questões que a ela subjazem no processo de aprendizagem de uma língua, aplicamos, no contexto previamente relatado, um questionário composto por três perguntas que contemplam aspectos concernentes ao conhecimento da língua espanhola, bem como às imagens que os alunos revelam acerca dela. Esses elementos nos proporcionaram informações sobre o conhecimento dos alunos sobre a diversidade do espanhol. É relevante citar que os 35 estudantes que participaram da pesquisa ainda não haviam tido nenhuma aula de língua espanhola com os professores que ministravam a disciplina no LABLIN, de modo que todo o conteúdo aportado pelas respostas ao questionário reflete a concepção de língua espanhola do aluno até então. São essas as questões a que nos referimos:

1. Você já estudou espanhol ou teve contato com a língua alguma vez (filmes, viagens, livros)? Por que optou por estudar essa língua?

\footnotetext{
${ }^{3}$ Dados referentes ao primeiro semestre de 2011 - quando se iniciou o projeto.
} 


\section{Revista do SELL}

v. $4, n^{\circ} .1$

ISSN: $1983-3873$

2. Você acha o espanhol uma língua fácil? Por quê?

3. Você acha que existem diferenças no espanhol dos países hispano-falantes? A variedade de que país você gostaria de aprender nestas aulas? Por quê?

Haja vista os objetivos inicialmente traçados, selecionamos, para análise, as respostas dadas à questão de número três. É relevante afirmar, no entanto, que para a análise e compreensão das respostas dadas a esta pergunta, utilizamos como subsídio os dados obtidos pelas respostas da primeira questão, uma vez que essas informações poderiam justificar, de algum modo, as posturas apresentadas na terceira. Assim, o conhecimento ou crença sobre a existência de uma ou mais variedades do espanhol poderia ter alguma relação com eventuais contatos ou estudo da língua em período anterior ao início das aulas do LABLIN.

Limitando-nos à análise da questão três, buscamos classificar as respostas a partir de dois critérios fundamentais: A) o aluno desconhece a variação na língua espanhola; B) o aluno reconhece a variação na língua espanhola. Aprofundando-nos no último critério, já que iria nos fornecer dados diretamente relacionados aos propósitos maiores desse trabalho, tratamos de dividi-lo em dois subgrupos:

B.1: o aluno reconhece a variação, mas não apresenta preferência por uma variedade específica:

B.1.a: porque diz não saber defini-las;

B.1.b: porque simplesmente não expõe sua preferência;

B.1.c: porque apresenta um posicionamento desprovido de estigmatização ${ }^{4}$.

B.2: o aluno expressa a sua preferência por alguma variedade do espanhol.

\subsection{Posicionando frente à diversidade linguística: análise dos dados}

A análise dos dados coletados mostra-nos que, dentre os 35 entrevistados, somente, três alunos $(A-8,6 \%)$ desconhecem a existência de variações dialetais na língua espanhola. Ou seja, a maioria absoluta (B - 91,5\%) é sensível ou pressupõem algum tipo de variação no que corresponde ao espaço geográfico onde o espanhol é língua oficial. É dentro do grupo dos que reconhecem a variação dialetal na língua

\footnotetext{
${ }^{4}$ Conforme o dicionário HOUAISS (2000), estigamatizar é fazer um julgamento ignominioso e irrevogável sobre algo, condenar, tachar. A palavra oriunda de estigma, que, conforme o mesmo manual,refere-se àquilo que é considerado indigno e desonroso.
} 


\section{Revista do SELL}

v. $4, n^{\circ} .1$

ISSN: $1983-3873$

espanhola que buscamos verificar a identificação que os alunos fazem com as diferentes variedades do idioma.

Assim, treze alunos (B.2.a - 37,1\%) demonstram preferência pelo que chamam "variedade espanhola" - o que corresponderia à imagem de uma língua homogênea falada na península; três estudantes (B.2.b - 8,6\%) demonstram interesse tanto pela "variedade espanhola" como pela da "América latina" - demonstrando uma percepção dicotomizadora entre o espanhol na América e o espanhol na Espanha. Por sua vez, quatro alunos (B.2.c - 11,4\%) identificam-se com variedades americanas, sendo dois com o "espanhol mexicano", um com a "variedade do Chile e Argentina" e outro com a variedade usada pelos países andinos.

Somam-se ao grupo dos que acreditam existir uma variação dialetal do espanhol, onze alunos que não declaram especificamente por qual das variedades teriam maior interesse, sendo cinco deles (B.1.a - 14,3\%) por não saberem identificar ao certo quais seriam as variedades existentes, quatro (B.1.b - 11,4\%) por motivos não explicitados e, finalmente, três (B.1.c - 8,6\%) por um posicionamento desprovido de estigmatização, tal como observamos nas palavras dos próprios alunos ao responderem a pergunta "a variedade de que país você gostaria de aprender nestas aulas?":

$(09)^{5}$ Todas que forem possíveis! Porque acho interessante e quero aprender.

(18) Não faz diferença.

(20) Gostaria de aprender todas as variedades.

O seguinte quadro resume os dados expostos até o momento:

\footnotetext{
${ }^{5}$ Os números referem-se à identificação do aluno em nossos dados (totalizando 35 alunos).
} 


\section{Revista do SELL}

v. $4, n^{\circ} .1$

ISSN: $1983-3873$

\begin{tabular}{|c|c|c|c|c|c|c|}
\hline \multicolumn{6}{|c|}{ GRUPOS } & NÚMEROS (\%) \\
\hline$A$ & \multicolumn{5}{|c|}{ Desconhece variação } & $03(8,6)$ \\
\hline$B$ & \multicolumn{5}{|c|}{ Reconhece Variação } & $32(91,4)$ \\
\hline & \multicolumn{5}{|c|}{ Sem Preferência } & $12(34,3)$ \\
\hline & \multirow{3}{*}{1} & a & \multicolumn{3}{|c|}{ Por não saber identificar as variedades; } & $05(14,3)$ \\
\hline & & $\mathrm{b}$ & \multicolumn{3}{|c|}{ Por ausência de posicionamento explícito; } & $04(11,4)$ \\
\hline & & C & \multicolumn{3}{|c|}{ Por um posicionamento desprovido de estigmazação } & $03(8,6)$ \\
\hline & \multirow{7}{*}{2} & \multicolumn{4}{|c|}{ Com Preferência } & $20(57,1)$ \\
\hline & & $\mathrm{a}$ & \multicolumn{3}{|c|}{ Pela "variedade espanhola" } & $13(37,1)$ \\
\hline & & $\mathrm{b}$ & \multicolumn{3}{|c|}{ Pela "variedade espanhola"+"Variedade Americana" } & $03(8,6)$ \\
\hline & & C & \multicolumn{3}{|c|}{ Por alguma variedade americana } & $04(11,4)$ \\
\hline & & & & "Mexicana" & 02 & \\
\hline & & & 2 & "Chilena ou Argentina" & 01 & \\
\hline & & & 3 & "Países Andinos" & 01 & \\
\hline \multicolumn{6}{|c|}{ Total } & $35(100)$ \\
\hline
\end{tabular}

Quadro 1. Da relação entre alunos entrevistados e identificação de variedades do espanhol.

A análise atenta desses dados aporta-nos informações preciosas. A primeira delas decorre do alto índice de alunos que, mesmo não familiarizados com a reflexão metalinguística ${ }^{6}$, acusam algum tipo de percepção (ou pressuposição) de que a língua espanhola apresenta variedades dialetais. Vejamos como alguns desses estudantes respondem a pergunta: "Você acha que existem diferenças no espanhol dos países hispano-falantes?":

(1) "Sim, tem diferença";

(2) "Acredito que sim";

(3) "Acho que existe alguma diferença";

(4) "Acredito que sim, como ocorrem com os países que falam a língua portuguesa. Porém não tenho conhecimento destas diferenças."

(5) "Acredito que sempre terá variedades nas línguas"

\footnotetext{
${ }^{6}$ Considerando que a não-familiaridade deva-se à carência de contato com situações que os levem a pensar sobre a língua e seu uso.
} 


\section{Revista do SELL}

v. $4, n^{\circ} .1$

ISSN: $1983-3873$

A recorrência dos verbos "acreditar/achar" - expressões que modalizam as asseverações enunciadas - parece nos indicar que a constatação da variação na língua espanhola pode ter sido resultante de uma reflexão pouco aprofundada e que, talvez, tenha sido despertada logo após se depararem com a terceira pergunta do questionário.

Em especial, encontramos no enunciado (4) um forte indício de uma das possíveis causas despertadoras da consciência de variação na língua estrangeira. Tal como lemos, a crença de que há diferenças regionais no espanhol provém do conhecimento empírico que 0 aluno possui sobre sua língua materna, de modo que espera encontrar o mesmo comportamento na língua estrangeira. É importante salientar que todos os exemplos apresentados pertencem a alunos que nunca estudaram a língua espanhola de forma sistemática e que, portanto, não tiveram oportunidade de refletir consistentemente sobre a variação na língua alvo.

Diante da pressuposição, quase que comum entre alunos brasileiros aprendizes de $\mathrm{E} / \mathrm{LE}$, de que existe uma diversidade geolinguística no espanhol, julgamos que o conhecimento despertado pela experiência que tem o falante com sua língua materna (PB) pode ser uma poderosa ferramenta no ensino de uma língua estrangeira. Isso porque é mais fácil procurar na língua do outro fenômenos que se assemelham aos de nossa língua materna. Assim, parece-nos que por esse caminho começamos a despertar nos alunos a consciência da inerente relação entre homem e língua, haja vista que a diversidade espacial facilmente detectável deve-se a que imprimimos na língua características correspondentes a necessidades e particularidades de cada comunidade.

Dirigindo-nos propriamente aos alunos que demonstram interesse por conhecer alguma variedade específica, verificamos uma expressiva preferência pelo que chamam de "variedade espanhola". Como já observado brevemente nos estudos de dialetologia, tratar como homogêneo o espanhol utilizado na península é um equívoco (MONTES GIRALDO, 1987; MORENO FERNÁNDEZ, 2000). No entanto, é natural que essa generalização ocorra entre alunos em contato inicial com o idioma. Por outro lado, esse tipo de afirmação deve possuir cada vez menos espaço à medida que o estudante avance no conhecimento da língua. Para tanto, cabe, mais uma vez, à figura do professor mostrar-Ihe que, mesmo na península - onde a dimensão territorial é menor, em comparação ao continente americano -, há uma grande diversidade cultural, o que, como sabemos, implicará variações no uso da língua.

Com esse propósito, o docente deve assumir uma postura prática que articule as "vozes, passando, sempre que necessário e possível, a palavra para as muitas vozes, os 


\section{Revista do SELL \\ v. $4, n^{\circ} .1$ \\ ISSN: $1983-3873$}

muitos sotaques, que representem as muitas realidades e histórias que conformam a riqueza desse mundo" (GONZÁLEZ, 2010, p. 30). Assim, a prática pedagógica abriria espaço para a citação, deixando de simplesmente "falar sobre", para dar palavra "as muitas vozes", isto é, "instalar a polifonia" refletida na diversidade da prática línguistica (GONZÁLEZ, 2010, p. 30). Ainda nesse contexto, faz-se também pertinente resgatar em aula a variedade do espanhol utilizada na zona insular do país, bem como a diversidade de línguas e culturas que, juntamente ao castelhano, coabitam a Espanha - esse é o caso do catalão, galego e o basco, por exemplo.

Mas que razão justificaria essa identificação quantitativamente expressiva com a variedade "além mar" quando compartilhamos fronteira terrestre com todo um continente hispânico? Parte dessa preferência pode ser atribuída, com vimos, à política conhecida como "la lengua es nuestro petróleo" (GODOI, 2010), frase que indica o interesse econômico do país em vender aquilo que possui ilimitadamente. É evidente que junto a essa difusão propagam-se também os aspectos culturais e linguísticos da nação.

O "êxito" desse tipo de investimento político-econômico pode ser verificado, entre outros, (I) na massiva preferência dos estudantes pelo castelhano falado naquela nação como apontam nossos dados; (II) na força editorial do país, facilitando o acesso aos materiais didáticos espanhóis e suprimindo editoras hispano-americanas - as quais, supomos, poderiam abordar a heterogeneidade linguística e cultural no continente; (III) na exaltação da "variedade castelhana" feita pelos que fazem manuais normativos e didáticos da língua, como apontam os trabalhos de Ponte (2010) e Araujo (2009).

Finalmente, também atribuímos a expressiva identificação com o espanhol falado na península a uma "auto-desvalorização" que condena a América Latina ao estigma da pobreza e subdesenvolvimento. Assim, o velho mundo, passa a ser visto como detentor do "original", "principal" e "correto", tal como contemplamos nas respostas dos alunos:

(6) "Gostaria de aprender o espanhol original".

(7) "gostaria de aprender o espanhol da Espanha por ser de onde surgiu tudo, e ser o principal”.

(8) "gostaria de aprender a variedade que se fala na Espanha. Pois parece que eles falam menos enrolados".

Curiosamente, outros enunciados apontam um compartilhamento de preferências que envolve tanto a "variedade peninsular" como a "variedade hispano-americana". No 


\section{Revista do SELL}

v. $4, n^{\circ} .1$

ISSN: $1983-3873$

entanto, argumentos como "um país influente", bem como a observação da ordem que os alunos conferem ao "espanhol da Espanha" no texto, pode nos levar a pensar que essa variedade continua a ocupar uma posição privilegiada em relação às demais.

(10) Acredito que sim. Espanha e América do sul (Argentina e Chile)

(11) Acredito que haja diferença no sotaque. Espanha e até países latinos. A Espanha por ser um país influente e os latinos por fazerem fronteira com o Brasil. (12) Sim, Espanhol da Espanha e o da América.

Além disso, constatamos no enunciado (10) a opção pela variedade "hispanoamericana" restrita a países de maior expressividade sócio-econômica como Argentina e Chile. O enunciado (11), por sua vez, mostra uma postura favorável às variedades "hispano-americanas" fronteiriças, ignorando, consequentemente, as demais variedades.

Pudemos perceber, nos enunciados de quatro alunos, o interesse ou preferência pelas variedades hispano-americanas. Esses dados revelam-nos que tal opção se relaciona a alunos com um contato mais efetivo com a língua, seja por músicas, cinema, arte, gastronomia ou, ainda, por uma experiência mais ativa que envolve o contato com falantes nativos ou brasileiros que vivem em países da América Hispânica.

(13) Acredito que não seja uma língua difícil, que haja diferença entre as línguas e gostaria de aprender a variedade dos países andinos.

(14) Sim, México. Tive mais contato com músicas e gostei.

(15) Sim, Chile, Argentina. Porque pretendo viajar para estes países pois, tenho amigos lá.

(16) Sim, algumas expressões são bem diferentes variando de país em país. Às vezes também o acento varia. Gosto mais do espanhol mexicano. Não sei porquê.

De modo oportuno, concordamos com CELADA (2008) ao enfatizar a necessidade que os brasileiros têm de estudar/aprender espanhol haja vista que "habitamos o espaço de enunciação do Cone Sul e, nele, espanhol e português são línguas vinculadas a um processo político de integração regional" (CELADA, 2008, p. 6). Aprender a variedade dos países hispano-americanos representa uma possibilidade de "conhecer o outro", estreitando relações de interesses que favoreçam ao aprendiz brasileiro um enriquecimento pessoal e também profissional. 


\section{Revista do SELL \\ v. $4, n^{\circ} .1$ \\ ISSN: $1983-3873$}

Próximos de encerrarmos, é pertinente que avaliemos em que medida a escolha do aluno por uma variedade hispano-americana reflete um interesse por países que desfrutam de um estado de maior relevância política e econômica no continente. Nesse sentido, os três últimos enunciados e o enunciado (10) apontam preferência pelas variedades do México, do Chile e da Argentina. É então, a partir desses dados, que nos indagamos sobre o por quê de os alunos não escolherem países como, por exemplo, o Paraguai, a Bolívia, o Equador, a Guatemala ou a Nicarágua como representantes de uma variedade de interesse.

Assumindo que os expressivos indicadores sócio-econômicos que apresentam a Argentina, o Chile e o México são fatores que contribuíram para a preferência por essas variedades, levantamos a hipótese de que a restrição às variedades dos três países também se deve à percepção de que eles desempenham, no contexto da América, um papel semelhante ao da Espanha. Caracterização que acreditamos poder levar o aprendiz a sustentar uma imagem de status, de certo "poder", caso queira e se disponha a aprender uma dessas variedades.

Em última análise, observemos o enunciado (13) que, como lemos, volta-se à(s) variedade(s) dos países andinos. Como observado no avanço das aulas do LABLIN, o enunciador do fragmento (13) justifica sua escolha dizendo que a região desperta especial interesse entre os agrônomos por se destacar no setor econômico primário. Além disso, acrescentou que é simpático à cultura andina. É, portanto, entre razões profissionais, ideológicas e pessoais que o aluno se vê diante de países que podem the oferecer contribuições e, a partir disso, identifica-se e revela o seu interesse pela possibilidade de aprender a língua e, por conseguinte, sua(s) a(s) variedade(s).

\section{Considerações finais}

Procuramos, neste texto, apresentar as principais propostas de divisão dialetal da língua espanhola e algumas considerações acerca de uma visão homogênea da língua que, disseminada principalmente por algumas posturas políticas, ainda é compartilhada no cenário nacional e internacional. Tais políticas ganham contornos ideológicos que, somados a outros fatores, passam a construir no imaginário do brasileiro posturas vinculadas ao preconceito linguístico como, por exemplo, na aceitação de que há uma única variedade peninsular (madrileña) e que é ela a que se deve aprender. 


\section{Revista do SELL}

v. $4, n^{\circ} .1$

ISSN: $1983-3873$

Posteriormente a essas discussões, buscamos refletir acerca das respostas dos alunos do LABLIN sobre as percepções da diversidade do espanhol e o anseio em aprender uma ou outra variedade da língua. Durante a análise dos dados, suscitamos que os incentivos políticos espanhóis em torno da língua e de seu ensino geram uma maior procura por essa variedade. Quanto à escolha da variedade hispano-americana, notou-se a circulação de uma imagem de que o espanhol da América também é homogêneo, fato que consideramos ser consequência das influências de um cenário político-ideológico que envolve a língua alvo e do desprezo pelas reflexões oriundas da dialetologia hispanoamericana. Soma-se a essa imagem, um pragmatismo que desperta no aluno o interesse pela busca de vantagens pessoais e profissionais.

Atendo-nos a alguns dos aspectos abordados no decorrer deste texto, buscamos encontrar alguns dos fatores que podem contribuir para a constituição da identidade dos alunos, nos processos de identificação, durante a aprendizagem da língua. Assim, observamos as visões estigmatizadas que se costumam associar à língua espanhola e, em contraoposição, argumentamos sobre a heterogeneidade inerente ao castelhano por meio do levantamento de algumas propostas de divisão dialetológica. Isso para também despertar no professor a necessidade de trabalhar com a heterogeneidade da língua espanhola "de forma que o aprendiz se valha dela para intensificar o seu processo de pertencimento cultural ao ambiente no qual vive" (PARAQUETT, p.143, 2010), isto é, a partir de um ensino de base intercultural. Espera-se, dessa maneira, despertar nos alunos a consciência da importância da diversidade, acumulando esforços em uma prática de ensino que os envolva em uma "atmosfera" de interculturalismo; esboçando um microcenário do que é o complexo mundo hispânico.

Considerar a diversidade da língua é, assim, respeitar a cultura, a herança, os hábitos de um povo. É reconhecendo, pois, a sua própria identidade e (des)estabilizandoa via contato com outras que o aprendiz se (re)forma, se(re)constrói:

"A identidade de um indivíduo se vincula aos bens patrimoniais que pertencem a sua comunidade cultural. Isso implica que esse indivíduo precisa aprender normas, valores, costumes, o que só pode acontecer no contato com o outro porque, isoladamente, ninguém pode aprender o que se faz socialmente. Daí que apenas formamos (ou construímos) nossa identidade no diálogo com outras pessoas e outras culturas. E, de novo, como professores de línguas estrangeiras esse é um privilégio que vivemos todos os dias na nossa prática profissional. Portanto, o processo de construção da identidade é um processo social e não se limita aos muros da escola, apesar desta exercer um papel fundamental" (PARAQUETT, p. 144, 2010). 


\section{Revista do SELL}

v. $4, n^{\circ} .1$

ISSN: $1983-3873$

\section{Referências}

ARAUJO, L. S. "La gramática lo propuso, pero he escuchado...": um estudo comparativo sobre o uso dos pretéritos indefinido e perfecto segundo a perspectiva da gramática normativa e a impressão de uso efetivo de hispanofalantes. 2009. 70 f. Monografia de Conclusão de Curso (Bacharel em Letras) - Faculdade de Ciências e Letras, Universidade Estadual Paulista "Júlio de Mesquita Filho", Araraquara, 2009.

BAKHTIN, M. Discurso na vida e discurso na arte (sobre poética sociológica).Tradução de Carlos Alberto Faraco \& Cristóvão Tezza, 1926.

BAKHTIN, M. Estética da Criação Verbal. São Paulo: Martins Fontes, 2006.

BAGNO, M. Preconceito Linguístico: o que é, como se faz. 16 ed. São Paulo: Loyola, 2002.

CAMACHO, R. G. Sociolinguística: Parte II. In: MUSSALIM, F.; BENTES, A. C. (Orgs). Introdução a linguística: domínios e fronteiras. 2 ed. São Paulo: Cortez, 2001. 2 v. p.2147.

CARAVEDO, R. El espacio en la lingüística de la variación. In: CASTAÑER, R.M.; ENGUITA, J.M. (Orgs). Archivo de filología aragonesa: in memoriam Manuel Alvar. Zaragosa: Institución Fernando el Católico. 2004. 2v. p.1119-1129.

CELADA, M.T. "O que quer, o que pode uma língua? Língua estrangeira, memória discursiva, subjetividade". Letras, 18: 13-29, Campo Grade, 2008.

FIORIN, J. L. Considerações em torno do projeto de Lei 1676/99. In: FARACO, C.A. Estrangeirismos - guerras em torno da língua. 2.ed. São Paulo: Parábola, 2002.

GERALDI, J.W. Ancoragens: estudos bakhtinianos. São Carlos: Pedro \& João Editores, 2010.

GODOI, E. Ensino de línguas estrangeiras e colonialismo cultural: o caso do espanhol. In: SANTOS, H., R.; ANDRELINO, P.J. (Orgs). Linguagens em interação II: leitura e ensino de línguas. Maringá: Clichetec, 2010.

GONZÁLEZ, N. M. Iniciativas para a implantação do espanhol: a distância entre o discurso e a prática. In: BARROS, C. S.; COSTA, E. G. M. Espanhol: ensino médio. Brasília : Ministério da Educação, Secretaria de Educação Básica, 2010. p. 25-54.

HENRÍQUEZ UREÑA, P. Observaciones sobre el español en América y otros estudios filológicos. Buenos Aires: Academia Argentina de Letras, 1976.

HJELMSLEV, L. Prolegômenos a uma teoria da linguagem. São Paulo, Perspectiva, 1975. HOUAISS. Dicionário eletrônico Houaiss da língua portuguesa. São Paulo, Objetiva, 2000. MASSINI-CAGLIARI, G. "Language Policy in Brazil: monolingualism and linguistic prejudice". Language Policy, 3: 3-23, Dordrecht, 2004.

MONTES GIRALDO, J. J. Dialectología general e hispanoamericana. Orientación teórica, metodológica y bibliográfica. 2. ed. Bogotá: ICC, 1987.

MORENO FERNÁNDEZ, F. Qué español enseñar. Madrid: Arco libros, 2000.

PARAQUETT, M. Multiculturalismo, interculturalismo e ensino/aprendizagem de espanhol para brasileiros. In: BARROS, C. S.; COSTA, E. G. M. Espanhol: ensino médio. Brasília, Ministério da Educação, Secretaria de Educação Básica, 2010, p. 137-156.

PONTE, A. S. A variação linguística na sala de aula. In: BARROS, C. S.; COSTA, E. G. M. Espanhol: ensino médio. Brasília, Ministério da Educação, Secretaria de Educação Básica, 2010, p. 157-174.

NUMHAUSER, J. [compositor]. Todo cambia. In: SOSA, M. Oro. [S.I.]: Universal, 1995. 